\title{
LA IGLESIA CONTINENTAL QUE LLEGABA AL CONCILIO. ECLESIOLOGIA DE LOS VOTA DE LOS OBISPOS LATINOAMERICANOS PARA EL CONCILIO VATICANO II
}

The Continental Church Coming to the Council. Ecclesiology of the Vota of the Latin American Bishops for the Second Vatican Council

Rodrigo Polanco *

RESUMEN: El artículo revisa todas las propuestas (o vota) enviadas por los obispos latinoamericanos y de El Caribe a la Comisión Antepreparatoria del Concilio Vaticano II sobre los temas que deberían ser tratados en la asamblea conciliar, para descubrir, a través de ellos, la eclesiología subyacente en los obispos que participaron en el concilio. El texto se divide en dos partes. Un estudio estadístico de los 395 vota o propuestas episcopales. Y, a continuación, un estudio de todos los temas que dicen relación con la Iglesia, su naturaleza y su misión, para descubrir más profundamente la eclesiología subyacente. La investigación -que no había sido hecha antes con la totalidad de los vota- muestra que, si bien en lo temático el episcopado latinoamericano y caribeño no muestra especial novedad con respecto al resto del mundo, sin embargo, se pueden aprecia algunas actitudes y acentuaciones que sí presagian el novedoso talante eclesial que empezará a despuntar en el continente a partir de la experiencia conciliar.

PALABRAS CLAVE: Obispos. Latinoamérica. Vota. Concilio Vaticano II. Comisión Antepreparatoria. Eclesiología. Iglesia. Historia del Concilio Vaticano II.

ABSTRACT: The article reviews all the proposals (or vota) sent by the Latin American and Caribbean bishops to the Antepreparatory Commission of the Second Vatican Council on subjects that should be discussed by the conciliar assembly.

\footnotetext{
* Pontificia Universidad Católica de Chile, Santiago, Chile.
} 
The purpose is to uncover the underlying ecclesiology of the pastors partaking in the council. The text is structured in two parts. A statistical study of the 395 vota or episcopal responses. And, subsequently, a study of all subjects relating to the nature and mission of the Church, so as to go deep into the underlying ecclesiology. Such a research -not thus far undertaken considering all the votareveals Latin American and Caribbean bishops not specially original in contents, but showed nevertheless some attitudes and accents which foreshadow the new ecclesiastical disposition which will begin to emerge on the continent as a result of the conciliar experience.

KEYWORDS: Bishops. Latin America. Vota. Vatican Council II. Antepreparatory Commission. Ecclesiology. Church. History of Vatican II.

\section{Introducción}

A penas cinco meses después de la convocación al Concilio por parte Adel Papa Juan XXIII, se le pidió a todos los obispos del mundo que enviaran su parecer sobre las materias que deberían ser tratadas en la futura asamblea conciliar. La respuesta a esa solicitud, que puede ser considerada como la primera intervención oficial de los obispos en el Concilio Vaticano II, si se estudia con cierta detención, puede reflejar algunos aspectos característicos del modo de concebir la Iglesia y su misión de parte de los obispos consultados. El objetivo del presente trabajo es, entonces, revisar todas las respuestas de los obispos latinoamericanos y del Caribe a dicha consulta, a fin de extraer su propia comprensión de la Iglesia, previa al concilio. El estudio de lo que pensaban los obispos del continente antes del concilio (1959-1960) - reflejado en sus propuestas y deseos - nos permite comprender cómo llegaron esos obispos al concilio y nos podrá ayudar luego a comprender su actuar en el concilio y en el pos concilio. Es evidente que los obispos no fueron los únicos actores en este gran proceso de renovación eclesial en torno al Concilio Vaticano II, pero fueron actores importantes. Es necesario, pues, discernir cuál fue su real aporte y cómo fue también su propio proceso de cambio, ya que su participación en el concilio fue parte de un amplio proceso de renovación ocurrido en la Iglesia latinoamericana en la década del 60 del siglo pasado, que culminó con la II Conferencia General del Episcopado Latinoamericano en Medellín (Colombia), en 1968, y con todo lo que ello significó para el futuro de las iglesias del continente. Los procesos de cambio siempre tienen muchos actores y etapas. Una buena comprensión de aquellos procesos necesita y supone una buena comprensión de cada una de esas etapas y actores. En ese contexto, nuestro estudio es un aporte puntual - pero necesario e indispensable - a la comprensión de todo ese proceso. 
El presente trabajo ${ }^{1}$ tendrá dos momentos: una revisión estadística de todas las respuestas a la consulta (los vota), lo cual entrega un panorama de la realidad y el pensamiento eclesial del episcopado latinoamericano previo el concilio. Y, a continuación, el estudio de todos los vota que dicen relación más inmediata con la auto comprensión de la Iglesia por parte de los obispos, lo cual implica centrarnos en aquellas respuestas que se refieren directa o indirectamente a temas eclesiales. Al final, extraeremos algunas primeras conclusiones eclesiológicas - siempre provisorias - que pueden permitir una mejor interpretación de lo que ocurrirá luego en el concilio.

\section{Mirada estadística general}

La carta de consulta a todos los obispos y prelados del mundo, a los superiores de congregaciones, órdenes e institutos de vida consagrada (masculinos), además de los institutos de estudios superiores del mundo y las congregaciones romanas, fue enviada por el Cardenal Domenico Tardini, Secretario de Estado y presidente de la Comisión Antepreparatoria del Concilio Vaticano II, con fecha 18 de junio de 1959 (AD I, II-I, p. x-xi). Allí afirmaba:

El Sumo Pontífice desea ante todo conocer las opiniones o pareceres y reunir las sugerencias y deseos de los Excelentísimos Obispos y Prelados que por derecho son llamados al Concilio Ecuménico [...]

Ruego, pues, encarecidamente a Su Excelencia que me ayude comunicando a esta Pontificia Comisión, con toda libertad y sinceridad, las observaciones, sugerencias y deseos que le proporcionen su solicitud pastoral y celo por las almas en torno las materias y temáticas que puedan ser tratadas en el futuro Concilio Ecuménico.

De este modo, las materias y temáticas pueden atañer a algunos temas de la doctrina, a la disciplina del clero y del pueblo cristiano, a una actividad de cualquier naturaleza sobre la que la Iglesia hoy se ocupa, a las preocupaciones de mayor urgencia que la propia Iglesia debe afrontar en los tiempos actuales, o a cualesquiera otras materias que pareciera a Su Excelencia haya que exponer y examinar a fondo.

En la prosecución de esta tarea Su Excelencia podrá acudir, de manera discreta, a la sugerencia de eclesiásticos expertos y prudentes (AD I, II-I, p. x).

En Latinoamérica, de los 549 obispos consultados y presentes en el continente², es decir, en México, América Central, El Caribe y América

\footnotetext{
${ }^{1}$ He contado con la valiosa colaboración del licenciado en teología, Sebastián Asencio (Pontificia Universidad Católica de Chile), que ha realizado un prolijo trabajo de revisión estadística, traducción y sistematización de los vota latinoamericanos, que ha servido como base para el presente trabajo.

${ }^{2}$ Cf. los datos estadísticos en AD I, Indices, especialmente p. 343.355.371.
} 
del Sur ${ }^{3}$, respondieron 434 de ellos, la mayoría de manera personal, pero también algunos lo hicieron de manera conjunta, y otros todavía de ambas formas. Es decir, el 79\% de los obispos latinoamericanos respondió a la consulta. Esto significa que en el continente hubo un porcentaje mayor de respuestas que el promedio de todas las respuestas del mundo $(76,4 \%)$ y también, mayor que el promedio de las respuestas de los obispos de todo el mundo (77\%) (AD I, Indices, p. 209 y 211). Encontramos sus respuestas en las AD I, v. II (Consilia et vota episcoporum ac praelatorum), pars VI y VII. En el caso de las universidades católicas o facultades teológicas latinoamericanas, a diferencia de los obispos, solo respondieron tres de las diez consultadas: la Pontificia Universidad Xaveriana de Colombia, la Universidad Católica de Ecuador y la Pontificia Universidad Católica de Chile (30\%) (AD I, IV-II, p. 49-50.537-538.557-560, respectivamente). Notoriamente es el continente de más bajo número de respuestas entre los institutos de formación superior del mundo que, como promedio, respondieron en un $82 \%$ (AD I, Indices, p. 429-433). Sin embargo, no es posible saber con exactitud la razón de esta extraña falta de respuestas. Tal vez sea solo un cúmulo de situaciones coyunturales. En todo caso, en el número de respuestas episcopales se puede apreciar que, en el continente, desde el inicio, el acontecimiento conciliar fue tomado muy en serio.

Las repuestas se enviaron durante la segunda mitad del año 1959 y hasta los primeros meses de 1960. En total, se recogieron 395 respuestas o vota, incluidas las tres universidades. Cinco son respuestas conjuntas: la Conferencia Episcopal Mexicana, en la cual firman 37 obispos (13 de ellos no enviaron sugerencias particularmente ${ }^{5}$ ); la Conferencia Episcopal de América Central y Panamá (CEDAC-Panamá) ${ }^{6}$, en la cual firman 3 obispos de Costa Rica, 7 de Guatemala, 2 de Honduras, 1 de Nicaragua y 6 de San Salvador (de ellos, solo 4 obispos de Guatemala, uno de Costa Rica y uno de Honduras enviaron además sus propias contribuciones personales [6 de 19]); dos conferencias episcopales regionales de Brasil: la de la Provincia Eclesiástica de Belo Horizonte, con 9 firmas, y la de Rio Negro, con 4 firmas, todos los cuales no enviaron otras contribuciones personales; y dos pares de obispos colombianos enviaron un votum conjunto (el de Cartagena junto al de Barranquilla y el de Girardot junto al de Espinal). Otros 10 obispos

\footnotetext{
${ }^{3}$ En las AD se divide el continente en América del Norte (que incluye hasta México), América Central (en donde se incluye El Caribe) y América del Sur. Por eso, a continuación, también nosotros aquí entendemos por Latinoamérica u obispos latinoamericanos, desde México al sur, incluido todo el Caribe, de acuerdo a la geografía política de la época.

${ }^{4}$ Comparando con los demás continentes: Europa: 79,9\%; Asia: 70,2\%; África: 83,3\%; América del Norte (incluido México): 72,7\%; Oceanía: 68,5\%. Los superiores de congregaciones e institutos de vida consagrada: $64,5 \%$; y los institutos de educación superior: $82,2 \%$. Cf. AD I, Indices, s.l. Una interpretación de todos estos datos en FOUILLOUX, 1999, P. 98-100. ${ }^{5}$ Uno de los firmantes, A. Escalante, es el ex vicario apostólico de Pando (Bolivia) pero de origen mexicano y que, de regreso en México desde 1948, se dedicó al Seminario de Misiones. ${ }^{6}$ Único votum internacional. Cf. FOUILLOUX, 1999, P. 103.
} 
enviaron sus vota junto a sus auxiliares (2 de México, 2 de Ecuador, 1 de Bolivia, 3 de Brasil, 1 de Colombia y 1 de Perú). Y dos obispos adjuntaron explícitamente la opinión de otros peritos: I. E. McManus, obispo de Ponce, Puerto Rico, que consultó al futuro perito conciliar F. J. Connell y al rev. T. Marijuán (AD I, II-VI, p. 648-652); y el arzobispo de Cuenca (Ecuador), M. Serrano, que adjuntó las opiniones que recogió entre religiosos y docentes (AD I, II-VII, p. 13-17). No es posible saber si los demás y en qué medida consultaron a otras personas. Es de suponer que algunos lo han hecho (MALLIMACI, 1992, p. 105), pero no podemos saber si es la tónica general. En cuanto al idioma, 362 respuestas son -como estaba pedido- en latín (aunque 20 de ellas introducen la respuesta en su lengua vernácula [español, italiano, francés, inglés]), 13 respuestas están escritas en italiano (5 de ellos son nuncios), 9 en castellano, 5 en francés, 4 en portugués y 2 en inglés. No parece ser una actitud contestataria, sino más bien, falta de práctica latina ${ }^{7}$. De hecho, varios cometen errores en el latín (cf. AD I, II-VI, p. 555; AD I, II-VII, p. 101). En cuanto a la extensión de los vota, la gran mayoría responde solo una o dos páginas de las Acta et Documenta (menos de 500 palabras). Unas 40 respuestas están entre las tres y cinco páginas y una decena puede superar esa cantidad, sin pasar de diez. Es del todo excepcional el que tres vota superen la decena de páginas, llegando al máximo, con el arzobispo de Guadalajara (México), J. Garibi, con 25 páginas (AD I, II-VII, p. 189-214) ${ }^{8}$. ¿La necesidad de escribir en latín, no habrá sido también una de las causas para esta tan frecuente concisión?

Por otra parte, es importante constatar que no se da, en general, una equivalencia entre la extensión de un votum (que podría estar indicando un mayor involucramiento en este inicio del proceso conciliar) y la participación posterior de ese mismo obispo en la asamblea conciliar. Tener presente eso permite también ponderarlos en su justa medida. Por ejemplo, si miramos a los alrededor de 30 obispos cuyos vota se extienden por más de tres páginas, lo que supondría un cierto mayor trabajo e interés previo por responder (o, tal vez, de algún perito consultado), fuera de 3 de ellos, que por diversas razones no pudieron asistir a la asamblea conciliar (Aguirre, Yerena [México], presentes solo en la primera sesión; y Pittini [República Dominicana], fallecido), solo 4 de ellos (De Castro Mayer, De Barros Câmara, Saboia Bandeira de Melo y De Proença Sigaud [todos de Brasil])

\footnotetext{
${ }^{7}$ M. Libardoni, prelado nullius de Huari (Perú) indica que "las múltiples ocupaciones [... de] este momento no [le] permiten una traducción directa al latín" (AD I, II-VII, p. 518); J. Hascher, prelado nullius de Juruá (Perú) se justifica porque vive desde 1920 "en la espesura africana o en la selva virgen de Brasil" (AD I, II-VII, p. 276); G. Warmeling, obispo de Joinvile (Brasil) piensa que un texto espontáneo y libre se "encuentra mejor en los matices de la lengua vernácula" (AD I, II-VII, p. 193); y Leopoldo Buteler, obispo de Río Cuarto (Argentina), explica que en castellano puede "ser más explícito en el planteo de los asuntos" (AD I, II-VII, p. 75).

${ }^{8}$ Los otros son el obispo G. de Proença (Jacarézinho, Brasil) (15 págs.) (AD I, II-VII, p. 180-195) y el obispo A. M. Ungarelli (Pinheiro, Brasil) (12 págs.) (AD I, II-VII, p. 286-298).
} 
aparecen entre los 30 obispos latinoamericanos con más participación en la asamblea conciliar (con 5, 13, 6 y 4 intervenciones orales y 23, 4, 18 y 5 intervenciones orales que no pudieron ser leídas o enmiendas escritas, respectivamente, en el total de las cuatro asambleas; además de otro número semejante de intervenciones orales o escritas que apoyaron con su firma [22, 11, 16 y 17 respectivamente]). Es un número comparativamente bajo de coincidencia. En cambio, otros no tienen intervenciones personales - ni escritas ni orales -, sino apenas cada uno firma un número total no mayor de 4 intervenciones escritas $u$ orales de otros (Verolino [Costa Rica], McManus [Puerto Rico], Mozzoni [Argentina] y Fariña [Chile]). Otros, aunque firman más intervenciones conjuntas, tampoco tienen ninguna intervención escrita u oral propia (Barbosa [Brasil], Castro [Colombia] y Bogarín [Paraguay]). $\mathrm{Y}$ otros, solo presentan 1 o 2 intervenciones escritas $\mathrm{u}$ orales personales en toda la asamblea, además de las firmas en común (Tortolo [Argentina], Zanini [República Dominicana], Serrano, [Ecuador], Esorto [Argentina] y Salinas [Chile]). Una participación aparentemente mucho menos notoria que los cuatro obispos arriba mencionados. Y si miramos esto mismo desde la perspectiva inversa, y revisamos ahora a los 30 obispos que tuvieron una participación más numerosa con sus intervenciones - ya sea escritas $\mathrm{u}$ orales - en las cuatro sesiones conciliares, nos encontramos con que 14 de ellos no enviaron vota porque todavía no eran obispos o fueron nombrados en esos mismos meses (Bueno Miele [Brasil], Cáceres [Uruguay], Da Silva Neto [Brasil], Devoto [Argentina], Grotti [Brasil], Henríquez [Venezuela], Lamartine [Brasil], McGrath [Panamá], Padin [Brasil], Picâo [Brasil], Przyklenk [Brasil], Quarracino [Argentina], Silva Henríquez [Chile] y Zazpe [Argentina]); otros 5, siendo consultados, tampoco enviaron vota (Caggiano [Argentina], De Sousa Lima [Brasil], Fragoso [Brasil], Ramos [Brasil], Távora [Brasil]); otros 7 no pasan las 3 páginas de extensión (750 palabras) (De Medeiros [Brasil], Rossi [Brasil] y Kémmerer [Argentina] con una página; Da Mota e Albuquerque y Gomes do Santos [ambos de Brasil] con dos páginas; Landázuri [Perú] y Helder Câmara [Brasil] con tres páginas); y solo 4 (los arriba mencionados) se encuentran entre los 30 que escribieron vota más extensos. Nuevamente, aquí no hay una relación directa entre la vitalidad conciliar y la alta o baja participación previa. Además, hay que tener en cuenta, igualmente, que hubo obispos muy activos en las sesiones, pero que nunca o rara vez presentaron ellos un texto escrito $\mathrm{u}$ oral, y solo aparecen como firmantes de observaciones escritas o de intervenciones orales en sala (vg. Helder Câmara) ${ }^{9}$. ¿Se puede presumir, entonces, que los obispos más activos en el momento previo, por alguna razón, no serán los más motivados en el desarrollo

\footnotetext{
${ }^{9}$ Presentó solo una intervención oral -sobre el capítulo II del esquema de episcopis-, que no pudo ser leída (AS II-V, p. 150-152), pero aparece firmando en 18 intervenciones orales y en 22 animadversiones escritas, varias de las cuales eran intervenciones orales que no pudieron ser leídas.
} 
de la asamblea? ¿O que estamos presenciando un cambio en los intereses $\mathrm{y}$ visiones eclesiales que implican un cambio de protagonistas? ¿O hubo muchos nuevos obispos? Todo esto nos debe hacer cuidadosos a la hora de interpretar la importancia de los vota y lo que están expresando. Sin duda, expresan lo que piensan los obispos, pero, tal vez, no es todo lo que ellos piensan, o hay más cosas implícitas, que irán emergiendo de a poco $^{10}$.

Ahora, de acuerdo a la geografía política de ese momento, el número de respuestas por países se ordena así: 37 de México, 4 de Costa Rica, 3 de Cuba, 6 de la Federación Británica del Caribe, 12 de Guatemala, 7 de Haití, 5 de Honduras, 1 de Honduras Británica, 1 de la Isla de Curaçao, 1 de las Islas de Bahamas, 3 de las Islas de Guadalupe y Martinica, 6 de Nicaragua, 4 de Panamá, 2 de Puerto Rico, 6 de República Dominicana, 6 de San Salvador (que en realidad es el votum común de la CEDAC-Panamá), 17 de Ecuador, 33 de Argentina, 14 de Bolivia, 116 de Brasil, 20 de Chile, 35 de Colombia, 3 de Guyana, 6 de Paraguay, 27 de Perú, 5 de Uruguay y 17 de Venezuela; además de las tres universidades.

Por otra parte, la ausencia de respuesta de 115 obispos del continente (21\%) se puede deber a variadas razones. Algunas, por la situación histórica del obispo. Por ejemplo, Raúl Silva Henríquez, que luego fue muy activo durante el Concilio Vaticano II, no respondió; muy probablemente porque recién fue ordenado obispo de Valparaíso (Chile) el 29 de noviembre de 1959. El proceso de instalación lo habrá tenido con otras preocupaciones más "urgentes", ya que hubo una carta recordatoria, dirigida por Mons. Pericles Felici, secretario de la Comisión Antepreparatoria, con fecha 21 de marzo de 1960, en donde rogaba "encarecidamente" a los que todavía no habían contestado, que le enviasen "una respuesta dentro del mes de abril" de 1960 (AD I, II-I, p. xiii). Semejante situación debió ocurrir también con las vicisitudes del arzobispado de Buenos Aires en ese año 1959 (tres obispos titulares durante ese año), de donde tampoco se recibió un votum. Otros consideraron que la respuesta dada en conjunto, y firmada por ellos, cumplía con lo pedido (cf., por ej., los obispos de S. Salvador [AD I, II-VI, p. 679-680]). También hubo varios de ellos - en torno a 29 - que, si bien "responden" a la carta, sin embargo, consideran que no tienen nada especial que decir, o solo indican que están muy abiertos a lo que el Papa o el resto del Concilio dirá. Ofrecen diversas razones. R. Isaza Restrepo, obispo de Ibagué (Colombia) afirma: “aunque consideré muy atentamente qué cosa podría proponer yo a Su Eminencia y a la Comisión Antepreparatoria del Concilio para ser examinado, nada me vino a la mente" (AD I, II-VII, p. 407). I. Lonati, prelado nullius de São José do Grajaú (Brasil), dice no tener "opiniones, sugerencias o nuevos vota para

${ }^{10}$ De allí la necesidad de comprar, luego, estos vota con las intervenciones episcopales durante las sesiones del concilio, para una mejor comprensión de todo el proceso conciliar continental. 
manifestar" ya que vive "en una región remota, en la selva de Maragnia, en donde no [tiene] contacto frecuente con las necesidades de este tiempo" (AD I, II-VII, p. 306). Y A. P. de Nadal, obispo de Uruguaiana (Brasil), espera "con gran gozo el Concilio", pero solo ofrece elevar oraciones "para que las materias propuestas por la Comisión ante-preparatoria [...] lleguen a feliz realización" (AD I, II-VII, p. 265). Es claro también que la edad de varios otros ha de haber sido un factor importante para no responder, y no podemos descartar la posibilidad de que muchos de los que no respondieron, tal vez, no vislumbraron la importancia de su propio involucramiento en lo que debía ser el Concilio. Esto último podría ser la razón por la cual, estadísticamente, la respuesta de los obispos "titulares", es decir, auxiliares, es considerablemente más baja que la del promedio. Solo 60 de los 106 consultados respondieron (un 56,6\%) (AD I, Indices, p. 343.355.371). El involucramiento de los obispos de territorios más alejados también es, en general, comprensiblemente más débil. Igualmente, una situación política de crisis pudo impedir una respuesta o una respuesta más elaborada, como debió ser el caso de Cuba, en donde responden solo 3 de los 8 obispos, es decir, el 37,5\% (AD I, Indices, p. 358). Con todo, para la no respuesta no es posible descubrir razones muy diversas a las de los otros continentes (cf. FOUILLOUX, 1999, p. 98-107). Lo mismo se debe decir acerca de la concisión de las respuestas. Probablemente todavía no se percibía la importancia de la voz de cada uno para el desarrollo del concilio. En consecuencia, estadísticamente, los vota están mostrando, de varias maneras y con bastante claridad, la fuerza del centro romano que hacía de los obispos, en muchos aspectos, solo receptores, disminuyendo así su capacidad propositiva y su influencia más allá de su región o diócesis.

\section{Cómo interpretar los vota}

Es sabido que no es fácil interpretar los consilia et vota episcoporum ac praelatorum, ya sea para extraer sus riquezas, como también para sobreponerse a sus límites, en cuanto expresión de un episcopado (MELLONI, 1990). Las dificultades radican en varios aspectos: conocemos la completa recopilación vaticana tal como ha sido editada, pero no tenemos a la vista los originales de cada uno de los obispos, con sus eventuales notas y observaciones. Tampoco está indicado, ni sabemos, quién fue el redactor, y en qué medida se utilizó literatura, estudios y/u opiniones ajenas (MELLONI, 1990, p. 561-566). Por otra parte, los vota deben ser comprendidos desde su origen y objetivo: no son una mirada global de toda la Iglesia del continente, sino la respuesta de los obispos a una pregunta bien precisa acerca del futuro concilio. En ese sentido hay que tomar en cuenta que, aunque la carta del cardenal Tardini deja "toda libertad y sinceridad" para responder, de alguna manera esa misma 
respuesta está algo condicionada por las cuatro temáticas que, aunque sea a modo de ejemplo, a continuación el cardenal expone: (1) "algunos temas de la doctrina", (2) "disciplina del clero y del pueblo cristiano", (3) alguna "actividad de cualquier naturaleza sobre la que la Iglesia hoy se ocupa", y (4) "las preocupaciones de mayor urgencia que la propia Iglesia debe afrontar en los tiempos actuales" (AD I, II-I, p. x). De hecho, uno puede percibir que los obispos van siguiendo esas cuatro temáticas - que eran, por lo demás, una manera eclesiástica clásica de mirar las cosas -, e incluso, algunos vota explicitan en su carta los cuatro títulos (o algunos de ellos): Doctrinae capita; Disciplina cleri; Disciplina populi; Actuositas Ecclesiae (AD I, II-VII, p. 61-63) ${ }^{11}$. Por otra parte, el hecho que se pida mantener una cierta reserva, también impide una consulta más amplia o un trabajo más comunitario y más abierto. Y, por supuesto, toda carta enviada directamente a la curia romana - con todo lo que ello significa en cuanto centro del poder (e incluso en cuanto al futuro de la misma carrera episcopal) - necesariamente influye, no solo en el contenido de lo expresado, sino también en el modo, en las acentuaciones y en los posibles silencios (MELLONI, 1990, p. 569-572). Las respuestas dependen mucho del receptor al que se le envían. Esto puede suscitar respuestas más obsequiosas o menos elaboradas, de acuerdo a lo que se perciba que se hará con esa información y a la utilidad real y efectiva de elaborar una opinión propia (FOUILLOUX, 1999, p. 107).

Al mismo tiempo, no se puede prescindir del contexto eclesial, político y geográfico para interpretar adecuadamente cada votum. Esto implica, en primer lugar, tener muy presente la fecha de su elaboración: segunda mitad del 59 y primera del 60. Juan XXIII había sido elegido hacía solo un año y estaba recién comenzando el paso del pontificado de Pío XII al "Papa bueno". La convocación al Concilio, hacía pocos meses, no permitía todavía vislumbrar cómo se desarrollarían los acontecimientos, ni su temática, ni sus desafíos. Todo esto para decir que no es fácil ni del todo justo hacer una comparación directa de los vota con la posterior intervención de los obispos latinoamericanos en las aulas conciliares, sin tomar en cuenta el importante cambio de contexto y el desarrollo vertiginoso del pensamiento eclesial/episcopal mundial en esos años. Pero también es importante tener presente la situación eclesial de cada país, que puede implicar temas y preocupaciones particulares de una región, que no se repiten de la misma manera en otras. Por ejemplo, más de un tercio de los vota del continente que piden una solución al tema "de máxima preocupación" de la pobreza (económica) del clero diocesano (AD I, II-VI, p. 221) ${ }^{12}$ vienen de México

\footnotetext{
${ }^{11}$ P. D. Henrici, obispo de Mar del Plata (Argentina). Se pueden ver, a modo de ejemplo, cómo se explicita parte de ese esquema en los obispos L. Aguirre, Culiacán (México), G. Viñamata, El Petén (Guatemala) o A. Barbisoti, Esmeraldas (Ecuador). Cf. AD I, II-VI, p. 179-188; 556-557; AD I, II-VII, p. 32-34, respectivamente.

${ }^{12}$ Cf. AD I, II-VI, p. 167.169.174.179.185.199.223.236.
} 
(9 votum, es decir, un tercio de los vota del país) y, el resto, se distribuye en los demás países de manera uniforme (uno o dos por país). Indica claramente un tema que tiene que ver con la situación propia de aquella nación y, tal vez, con el escenario legal de la misma Iglesia allí. Pero no parece ser un tema en el resto del continente, que como el resto de la población posee "sacerdotes muy pobres y también muy ricos" (AD I, II-VII, p. 276) ${ }^{13}$.

También es relevante la situación geográfica y, sobre todo, el momento político en el que cada uno de los obispos se encuentra al momento concreto de responder al cardenal Tardini. Por ejemplo, no se debería desconocer la relación del dictador de República Dominicana, Rafael Leónidas Trujillo (1942-1952), y su hermano Héctor Trujillo (1952-1960) con la Iglesia - con la firma del concordato entre la Santa Sede y la República Dominicana en 1954 -, para entender el sentido del votum del arzobispo de Santo Domingo, Ricardo Pittini, que pide sea solemnemente condenada la doctrina que "sostiene la absoluta separación de la Iglesia y el Estado" e insiste en que "no deben ser impugnados los gobernantes que, si bien no son perfectos, sin embargo luchan enérgicamente contra el comunismo" (AD I, II-VII, p. 662 $)^{14}$. Lo mismo habrá que decir acerca de la importancia que fue cobrando la toma de La Habana por parte de Fidel Castro, el 1 de enero de 1959, a la hora de juzgar, al menos algunos, de los vota que piden una explícita condena del comunismo, si bien es un tema de larga data en América latina ${ }^{15}$.

Con todo, teniendo en cuenta estas prevenciones, los vota, siendo una encuesta que ha sido respondida por la estupenda cifra del $79 \%$ de los consultados, nos permite hacernos una idea bastante confiable de la auto comprensión eclesial del episcopado latinoamericano (y de su entorno más cercano) previo al concilio, que ciertamente no es toda la Iglesia, ni tampoco indica con claridad todo el movimiento de ideas que empezaba a desarrollarse en las décadas previas a la asamblea conciliar y que decantó en las novedades postconciliares (POLANCO, 2020, p. 177-191). Pero explicita la forma de percibir la realidad eclesial por parte del episcopado de Latinoamérica y El Caribe al momento de la convocación al concilio,

\footnotetext{
${ }^{13}$ E. M. Corolo, prelado nullius de Guamá (Brasil).

${ }^{14}$ El texto parece estar más atento a su propia situación que a la del concilio: "[Procúrense] los medios por los cuales se pueda mantener la concordia, especialmente entre los pueblos y los gobernantes cristianos. Y que los católicos no impugnen a los gobernantes católicos de otras naciones, ni [tampoco impugnen] formas de gobierno diferente; y mucho menos [impugnen] a los obispos de otras naciones debido a que, tal vez, deben actuar, en medio de circunstancias muy diversas, en países [por ellos] desconocidos".

${ }^{15}$ Encontramos en torno a 50 vota que de distinta manera piden su condenación, ya sea con una declaración solemne (v.g. AD I, II-VI, p. 201.224.585; AD I, II-VII, p. 23.353.374), o indicando explícitamente su peligro para la Iglesia y la fe (v.g. AD I, II-VI, p. 220.605; AD I, II-VII, p. 42.56.333).
} 
y eso tiene una importancia para la comprensión, tanto de sus aportes al mismo concilio, como de la recepción conciliar en el continente.

\section{Eclesiología presente en los vota}

Teniendo en cuenta los criterios mencionados, para poder apreciar ahora específicamente la eclesiología de los obispos previa al concilio, hemos de recurrir a dos procedimientos de búsqueda. (1) De una manera más general, a una revisión de la temática global de los aspectos que podríamos llamar prácticos - considerados entonces como "disciplinares" -, es decir, litúrgicos, canónicos, pastorales, éticos; ya que detrás de ellos asoma un modo de percibir la identidad de la Iglesia y de su misión. En el Analyticus conspectus consiliorum et votorum quae ab episcopis et praelatis data sunt (AD I, Appendix vol. II, 2 partes) esta temática se pensaba como distinta de los "temas de la doctrina". Hoy día, esa no es una división muy feliz, pero era la forma de sistematizar y entender las cosas en esa época, entendiendo como posible una separación bastante neta entre doctrina y disciplina/ liturgia/práctica. Los vota reflejan también, en parte, esa manera de ver las cosas. Pero esos deseos y propuestas de los obispos acerca de la vida eclesial, precisamente porque expresan la idea de Iglesia presente en el inconsciente de los obispos, son una fuente útil - si bien limitada - para conocer algo de la eclesiología episcopal previa al concilio. Y, luego, (2) de una manera más específica y significativa, una revisión de aquellos temas doctrinales (eventualmente mencionados como canónicos, disciplinares o pastorales) en directa referencia con una teología de la Iglesia, en los cuales, a partir de las acentuaciones y opiniones eclesiológicas allí expuestas, también se pueden descubrir modos de comprender la Iglesia, fuentes inspiradoras y problemáticas sobre ella que habrían de ser pensadas en esa hora histórica. Con todo ello se podrán extraer algunas conclusiones que, si bien son todavía parciales, unidas luego al estudio de los aportes del episcopado latinoamericano al desarrollo del mismo concilio, pueden ayudar a una mejor comprensión de la recepción continental del Vaticano II y del caminar de la Iglesia latinoamericana en los años siguientes.

\subsection{Desde las preocupaciones "disciplinares" y "prácticas"}

En la inmensa mayoría de los vota latinoamericanos y caribeños (90\%) se encuentran propuestas que podríamos denominar prácticas o disciplinares -y más de un tercio de todos ellos, incluso contiene solo propuestas de tipo prácticas-, las que transparentan algo de cómo los obispos entendían la Iglesia y su estructura. En realidad, no son muy distintas de lo que encontramos en el Analiticus a nivel de todo el orbe. Son preocupaciones muy sentidas y compartidas por el episcopado de manera bastante universal. 
Sin embargo, podemos todavía rescatar ciertas particularidades, a partir de algunas acentuaciones o de la justificación de alguna determinada materia.

El tema que más sobresale (poco más de la mitad de los vota) es el deseo de una reforma, cambio o adecuación litúrgica en una muy variada gama de aspectos. Unos tienen que ver con la celebración de la eucaristía en la línea de una simplificación de su celebración que permita una mejor comprensión y participación de los fieles, eliminando costumbres obsoletas, normas enojosas y "dando más libertad en la Sagrada Liturgia para admitir símbolos, ritos, canticos y costumbres verdaderamente religiosas de cada pueblo, para que así se haga más universal y se elimine su carácter europeo" (AD I, II-VI, p. 598) ${ }^{16}$. Otros se refieren a los demás sacramentos, revisando la legislación y disciplina de su administración, simplificando su celebración e introduciendo la palabra de Dios más intensamente en su ritual, a fin de conseguir una más fructuosa participación en ellos. Pero también hay un inmenso conjunto de materias menores (desde agregar a san José en el canon de la misa, hasta eliminar las gotas de agua en el cáliz, pasando por la ampliación de las posibilidades horarias de las misas y distribución de la comunión o el fin de ciertos ayunos y preceptos y cambiar algunas oraciones del misal). Una decena de ellos pide que todo esto pueda ser resumido en un código de liturgia o en un directorio litúrgico pastoral. Por otra parte, unos 50 vota sugieren repensar las condiciones canónicas del matrimonio y renovar su legislación; unos 30 vota piden revisar más propiamente la teología de algunos sacramentos (renovando la doctrina, la praxis y el ministro de la confirmación o simplificando el rito del bautismo y de la unción de los enfermos o adaptando algunos preceptos y facultades relativas a la confesión). Y, obviamente, casi un tercio de los vota piden el uso de la lengua vernácula, tanto para la misa como también para los sacramentos e, incluso, para el breviario cuando es recitado privadamente. Este era un tema ampliamente sentido y la casi totalidad de los obispos que lo solicitan, lo hacen debido a la necesidad de "fomentar la piedad y una mayor comprensión de la liturgia" entre los fieles (AD I, II-VI, p. 544) $)^{17}$, ya que el pueblo latinoamericano no comprende el latín. Aunque hay también un puñado que insiste en la mantención del latín en la liturgia, o al menos en sus partes más esenciales ${ }^{18}$.

Y el otro tema que sobresale (más de un tercio de los vota) es la muy numerosa cantidad de sugerencias en torno a la vida del clero, tanto en sus aspectos más personales como también en la organización pastoral. Unos vota tienen que ver con simplificar y adaptar la vida del clero a los

\footnotetext{
${ }^{16}$ I. M. Holtermann, obispo de Willemstad (Isla de Curaçao).

${ }^{17}$ I. McEleney, obispo de Kingston (Federación Británica del Caribe).

18 "Toda la dificultad en el uso se la lengua latina en la liturgia proviene de la ignorancia de esa lengua entre los sacerdotes" (A Barbisotti, vicario apostólico de Esmeraldas [Ecuador] [AD I, II-VII, p. 33]).
} 
tiempos actuales, esto es, apuntan a una renovación en la forma de vida y del ministerio de los presbíteros (aunque también de los religiosos): pueden ser cosas prácticas, como revisar el uso de la sotana o poseer mayores facultades para desempeñar su tarea (poder llevar un altar portátil o poseer licencias para celebrar misas y sacramentos más adaptadas a las necesidades reales) ${ }^{19}$. O también pueden ser aspectos de la forma de vida sacerdotal, como mejorar su vida comunitaria y revisar la administración de sus bienes. Otros vota se refieren a una mejor organización del ministerio y actividad pastoral del clero, a fin de acercarlos más a sus fieles y mejorar su eficacia pastoral: muy diversas cosas, como una mejor redistribución de los sacerdotes, preocupación por el sustento de muchos clérigos, terminar con la inamovilidad de los párrocos, o una mayor preocupación por los sacerdotes enfermos y apoyo a los que viven en las regiones más alejadas. Y todavía otros, buscan mejorar la formación y vida espiritual del clero: se sugiere asegurar su vida espiritual con tiempos de retiro, ejercicios espirituales o acompañamiento. A todos estos vota habría que agregar todavía la inmensa cantidad (alrededor de un tercio también) que pide una simplificación y adaptación del breviario a la forma de vida contemporánea de la mayoría de los sacerdotes. Y, aunque menos, también un buen número (más de 50 vota) pide mayor atención a la formación sacerdotal y a los seminarios. Se trata, por una parte, de renovar la formación sacerdotal en cuanto a sus estudios y a su adecuación a las exigencias del mundo actual - sean exigencias culturales (en donde varían las opiniones, incluso opuestas), sean exigencias debidas a la escasez de clero (con seminarios interregionales, por ejemplo) -; como por otra parte, de reforzar la santidad de las costumbres y la vida del clero. En ese sentido, algunos insisten en procurar un mejor cumplimiento de los tres consejos evangélicos. Y cuando se habla de la vida religiosa - un tema, como tal, menos presente entre los obispos (y bastante ausente en lo que se refiere a la vida religiosa femenina) -, interesa más bien su trabajo pastoral y su ayuda a las necesidades de la diócesis. En realidad, se destaca el deseo de fortalecer/mejorar su relación con el clero secular (unos 30 vota) -buscando una mayor mancomunidad en el trabajo - y sobre todo con los obispos, donde sobresale la preocupación por la autonomía de los religiosos y porque se sometan a su autoridad (más de 50 vota), ya que la exención de los religiosos "daña gravemente la autoridad del ordinario del lugar y viene en detrimento del bien de las almas" (AD I, II-VI, p. 223) ${ }^{20}$.

Hay también una buena cantidad de vota (más de 80) que pide una reforma del Codex Iuris Canonici (CIC), o el agregar cosas que ahora no aparecen.

\footnotetext{
${ }^{19}$ Aunque en bajo número, también se encuentra quien quiere rigidizar las normas: "Que a quienes suelen asistir a espectáculos moralmente peligrosos, como el cine y otros de ese tipo, se les aplique una pena" (C. Fernández, obispo de Huajuapan [México]) (AD I, II-VI, p. 216).

${ }^{20}$ M. Miranda y F. Orozco, arzobispo y obispo auxiliar de México.
} 
Se pueden encontrar temas penales, litúrgicos, pastorales o disciplinares en general. Las sugerencias, sobre todo, van en la línea de la "reducción de las censuras, especialmente de las excomuniones" (AD I, II-VI, p. 638) la disminución de exigencias y la introducción de una nueva legislación sobre temas que parecen importantes, como puede ser la acción católica, temas de justicia y doctrina social, sobre las facultades y obligaciones de los párrocos, etc. Más que el código mismo como tal, lo que aquí interesa son cambios en variados temas de la legislación eclesiástica y, sobre todo, alivianar ciertas rigideces disciplinares, a la vez que legislar sobre las cosas que parecen hoy más centrales.

Es también suficientemente significativo (en torno a unos 70) el número de obispos que pide un examen y, sobre todo, una condenación de los errores modernos, como el laicismo, el liberalismo, el materialismo o el existencialismo, pero especialmente, el comunismo. En esto, más que una cuestión dogmática, parece estar presente aquella preocupación que había acompañado a la Iglesia del continente durante todo el siglo: el temor al comunismo, que repercutía, además, en una mayor sensibilidad social. Por eso, esta preocupación debe ser comprendida dentro del interés por la doctrina y la cuestión social, que trataremos particularmente un poco más adelante. Con todo, ello no obsta para que algunos obispos tengan otras preocupaciones que podríamos llamar más contemporáneas o contextuales. Algunos - sobre todo centroamericanos - piden una reflexión sobre el racismo (como H. M. Varin de la Brunelière, obispo de Fort-de-France et saint Pierre [Islas Guadalupe y Martinica]) (AD I, II-VI, p. 613-615) y otros - sobre todo brasileros - piden la condenación del espiritismo. Pero también, un número de vota - bastante menor que los anteriores (unos 30) - pide un pronunciamiento del concilio acerca de algunos temas éticos, ya sea de moral personal, como de costumbres sociales. Se menciona el tema de las guerras nucleares, la injusticia, la trata de personas o el hedonismo. En efecto, algunos están asustados por una "vida de inmoralidad hoy tan generalizada" (AD I, II-VII, p. 76) ${ }^{22}$, o manifiestan su desacuerdo con el uso de los métodos anticonceptivos; pero otros están más preocupados del lucro y de la deshonestidad en los negocios, o piden una definición de "justicia social internacional" y de la obligación de las naciones más ricas de aceptar la "emigración de una a otra región" (AD I, II-VI, p. 556) ${ }^{23}$ de las poblaciones más carentes, por mencionar solo algunos ejemplos. Finalmente, es conocido el pensamiento de G. Proença, obispo de Jacarézinho (Brasil) cuyo votum se planteó como una "lucha contra-revolucionaria" contra "los enemigos" de la Iglesia (secta Franco-Masónica, comunismo, judaísmo internacional y revolución) (AD I, II-VII, p. 180-195) (cf. Coppe

\footnotetext{
${ }^{21}$ F. Beckmann, arzobispo de Panamá (Panamá).

${ }^{22}$ L. Buteler, Obispo de Río Cuarto (Argentina).

${ }^{23}$ C. Luna, obispo de Zacapa (Guatemala).
} 
Caldeira, 2011, p. 394-395). Pero ese es un sentir más o menos aislado en el continente.

Finalmente, otros vota (unos 30) insisten en la necesidad de una mejor catequesis y la elaboración de un catecismo. Pero ese deseo no es el tema sobresaliente en ese momento. En cambio, un número importante - de distinta manera y en referencia a distintos temas - muestra una buena preocupación por la misión y la evangelización. No son pocos los vota que insisten en una redistribución del clero, en la necesidad de ir a los lugares de misión y en la búsqueda de nuevos modos de evangelizar (mejorar la predicación del evangelio ${ }^{24}$, fomentar las misiones parroquiales o entre los infieles, suscitar vocaciones misioneras para el continente, vivir en estado de misión, solicitar una mayor ayuda de las religiosas, promover el oficio de catequistas, etc.). Pero solo un obispo, cuando habla de "la Iglesia misionera", ve la necesidad de tratar "la cuestión de la asunción de las culturas indígenas" (AD I, II-VII, p. 201) ${ }^{25}$. Las culturas originarias seguían siendo completamente invisibles para la Iglesia. Ahora bien, todo esto hay que leerlo junto con lo que se dirá sobre los laicos y sobre la restauración del diaconado, cuyo trasfondo, en ambos casos, es la necesidad de una mayor colaboración en la evangelización (entendida muchas veces como tarea más bien propia de la vida clerical y consagrada). Este es un tema transversal, que aparece de manera muy práctica - y con problemas todavía de concepción teológica -, pero que revela una comprensión muy evangelizadora de la Iglesia en el continente, destinada a dar frutos en los años que seguirían.

\subsection{Desde los temas doctrinales}

\subsubsection{El tema mariológico}

Aunque no fue sugerido como un tema eclesiológico, sino del todo a se, dada su importancia en el contexto de los vota latinoamericanos y su auténtica relación con la eclesiología, es importante comenzar considerando que, largamente el tema 'doctrinal' más mencionado y de más alto consenso en el continente (junto a la restauración del diaconado permanente) fue la petición de una manifestación (solemne) del concilio sobre el papel mediador universal de María (89 vota, que suman 125 obispos), en donde casi todos ellos piden una "definición", "declaración" o "proclamación" "dogmática" o "de un dogma" (en torno a 110 obispos) ${ }^{26}$. Ese porcentaje

\footnotetext{
24 "La predicación, en primer lugar, debe ser más conforme al Evangelio: clara, breve, espontánea" (J. Mosquera, administrador apostólico del Vicariato de Zamora [Ecuador]) (AD I, II-VII, p. 37).

${ }^{25}$ G. M. de Morais Penido, obispo de Juiz de Fora (Brasil).

${ }^{26}$ Ej.: X. M. Ariz, vicario apostólico de Puerto Maldonado (Perú) (AD I, II-VII, p. 526).
} 
de obispos (28\%) es más alto que el promedio mundial de obispos que se refirió a este tema (22\%) (AD I, Appendix vol. II-1, p. 131-142). El mayor número de ellos pide una proclamación sobre la "mediación" de María, expresada como "mediación universal" o "mediación de todas las gracias" (unos 80 obispos) ${ }^{27}$, y una cantidad importante pide una proclamación de la "maternidad espiritual" (en torno a 40$)^{28}$. Una parte de ellos pide ambas cosas. Unos 6 piden que se le proclame "corredentora" del género huma$n^{29}$ y otros 5 solamente piden que se fomente su (sana) devoción ${ }^{30}$. Esto está mostrando que, en el continente, la inmensa mayoría de los obispos sigue una línea maximalista en su mariología. No deja de ser interesante que los obispos, en general, no se detienen a justificar su petición, sino más bien lo suponen como algo sabido y creído que, más que justificación, reclama una proclamación, ya que ello redundará en mayor fe y piedad en los fieles, además de que lo esperable de un concilio - es de suponer que ellos pensaban - era precisamente que incluyera definiciones ${ }^{31}$. En todo esto se percibe claramente una sintonía con la sensibilidad popular latinoamericana. Solo contados obispos ponen en guardia contra algunos peligros o cuidados al respecto, pidiendo que el concilio "expresamente recomiende mejores formas del culto mariano" (AD I, II-VI, p. 610) ${ }^{32}$; o que se evite aplicarle "carismas, privilegios, dignidades y poderes" más allá de los dogmas tradicionales (AD I, II-VI, p. 638)33; o que se proponga algún "título" "verdaderamente mariano-ecuménico", como el de "María

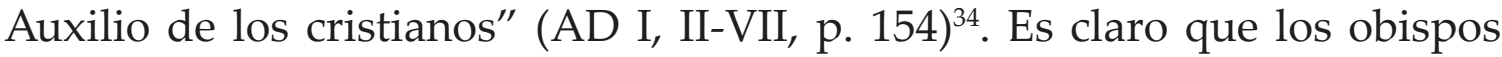
no percibían este tema como parte de un documento sobre la Iglesia, como finalmente llegará a ser en Lumen gentium.

\subsubsection{Sobre la Iglesia y su misión}

El tema de la Iglesia, desde una perspectiva doctrinal, se repite con frecuencia. Aparece al pedir una reflexión más completa sobre la naturaleza

\footnotetext{
${ }^{27}$ Ej.: F. Gómez, arzobispo de Antequera (México) (AD I, II-VI, p. 165); V. Maya, administrador apostólico de la prelatura nullius de El Oro (Ecuador) (AD I, II-VII, p. 29).

${ }^{28}$ Ej.: G. Manrique, obispo de Oruro (Bolivia) (AD I, II-VII, p. 111).

${ }^{29}$ Ej.: A. Meloto, obispo de Sololá (Guatemala) (AD I, II-VI, p. 553).

${ }^{30}$ Ej.: I. Gay, obispo de Basse-Terre et Pointe-à-Pitre (Islas de Guadalupe y Martinica) (AD I, II-VI, p. 609-610).

${ }^{31}$ Cf. L. M. Altamirano, obispo de Morelia (México): "Puesto que la piedad y devoción para con María, la Virgen Madre de Dios, crece cada vez más y todos los fieles la reconocen y veneran como madre y tienen la convicción de que por su mediación provienen todas las gracias, me parece oportuno que en el próximo Concilio se definan como verdades relativas a la fe la maternidad espiritual de la Bienaventurada Madre de Dios respecto de todos los hombres y su mediación universal" (AD I, II-VI, p. 226).

${ }^{32}$ I. Gay, obispo de Basse-Terre et Pointe-à-Pitre (Islas de Guadalupe y Martinica).

${ }^{33}$ F. Beckmann, arzobispo de Panamá (Panamá).

${ }^{34}$ A. Barbosa, obispo de Campo Grande (Brasil), expresado en el contexto de la promoción de la unidad de los cristianos. La misma preocupación ecuménica en A. Punzolo, nuncio en Panamá (AD I, II-VI, p. 640).
} 
o constitución de la Iglesia, pero también al solicitar el tratamiento de algunos temas que implican su relación con la sociedad. Con respecto a lo primero, más de 40 obispos piden - de distinta forma - que se "proponga", "confirme" o "desarrolle" una teología sobre la Iglesia ${ }^{35}$, pero que, en general, para ellos significa "reasumir", "exponer" o incluso "definir" 36 la doctrina del "Cuerpo místico" enunciada por Pio XII (para unos 30) ${ }^{37}$. Por ejemplo, para A. I. Jaramillo, obispo de Jericó (Colombia), "es necesario que se declare y defina abiertamente que aquella unión mística [= unión en el Cuerpo Místico de Cristo] posee un fundamento cósmico y ontológico, que es el hecho histórico de la Encarnación del Verbo" (AD I, II-VII, p. 408). Algunos otros de esos vota piden "retomar" y "exponer de modo más claro" y también "reestructurar" y "complementar" la doctrina eclesiológica del Vaticano ${ }^{38}$, mencionando diversas cosas que quedaron inconclusas (Cuerpo místico, notas de la Iglesia, potestad episcopal, laicos, etc.). Por ejemplo, J. de Jesús Alba, obispo auxiliar de Ciudad de México, piensa que "hay algunos dogmas definidos por el Vaticano que parecen merecer una declaración y aplicación ulteriores... [, otros] quedaron inconclusos... [y hay otros] cuya aclaración solemne parece oportuna, aunque sean propuestos por el magisterio ordinario" (AD I, II-VI, p. 250). Y algunos vota muestran que para varios obispos la eclesiología debería ser un tema importante en el Concilio. Por ejemplo, la Pontificia Universidad Católica de Chile considera que el "tema principal" que debiera ser tratado acerca de la "sagrada doctrina", tendría que ser "sobre la Santa Iglesia de Cristo", el cual conste de dos grandes aspectos: "sobre la naturaleza de la Iglesia" y "sobre la distribución orgánica de los miembros de la Iglesia" (AD I, IV-II, p. 558-560) ${ }^{39}$. El mismo A. Tortolo pide comprender la Iglesia "como nuevo pueblo adquirido por el Padre celestial, Esposa amadísima de Cristo Cabeza y Cuerpo Místico, y Templo vivo del Espíritu Santo en la tierra" (AD I, II-VII, p. 100). Y cinco obispos piden que se elabore una más "apropiada doctrina y praxis sobre la necesidad absoluta de la Iglesia de Cristo para la salvación eterna de cada uno" (AD I, II-VI, p. 240) ${ }^{40}$.

Unido a lo anterior está la preocupación por la unidad de los cristianos, que se repite en unos 35 obispos. Aunque - más bien en pocos - se encuentran palabras como "sectas", "disidentes", "herejes o cismáticos" (AD

\footnotetext{
${ }^{35}$ Ej.: G. M. de Morais, obispo de Juiz de Fora (Brasil) (AD I, II-VII, p. 200); F. Poirier, arzobispo de Port-au-Prince (Haití) (AD I, II-VI, p. 573).

${ }^{36}$ Ej.: E. Botero, obispo de Pasto (Colombia), junto a su auxiliar, I. Pimiento (AD I, II-VII, p. 427); N. Hayes, prelado nullius de Sicuani (Perú) (AD I, II-VII, p. 520).

${ }^{37}$ Ej.: M. A. Niedhammer, vicario apostólico de Bluefields (Nicaragua) (AD I, II-VI, p. 630).

${ }^{38}$ Ej.: A. Tortolo, obispo auxiliar de Paraná (Argentina) (AD I, II-VII, p. 100-101); I. B. da Mota, arzobispo de Vitória (Brasil) (AD I, II-VII, p. 267).

${ }^{39}$ Votum firmado por su rector, Alfredo Silva, arzobispo de Concepción, pero escrito por "profesores de la Facultad de Teología de dicha universidad".

${ }^{40}$ F. Ruíz, arzobispo de Yucatán (México). Cf. también F. Connell y las universidades de Colombia y de Chile.
} 
I, II-VI, p. 662; II-VII, p. 117 y 171, respectivamente $)^{41}$, el tono en estos vota es más bien respetuoso y preocupado. Es claro que el pensamiento de base está todavía en torno a la idea del "retorno" ${ }^{42}$. Así, I. C. Maurer, arzobispo de Sucre (Bolivia), coloca como el primero de sus seis temas "la posibilidad y los medios para atraer a las Iglesias disidentes y cismáticas a la unidad y verdad de la Iglesia Católica y a la sumisión dogmática, disciplinaria y filial al Papa, en cuanto legítimo sucesor de San Pedro y Vicario de Cristo en la tierra" (AD I, II-VII, p. 117). Pero el deseo de unidad, expresado en estos vota, parece ser sinceramente una verdadera preocupación eclesiológica y evangélica. Por ejemplo, se pide "innovar en cuanto a la disciplina eclesiástica respecto a los cristianos separados por herejía o cisma... [porque muchos de ellos consideran que con ella] faltamos a la caridad cristiana" (AD I, II-VI, p. 256) ${ }^{43}$; revisar "qué vínculo real existe entre la Iglesia y las iglesias separadas" (AD I, II-VI, p. 477) ${ }^{44}$; y establecer "qué cosa haya en la Iglesia de esencial por derecho divino, de modo que se le retire cualquier impedimento a quienes sinceramente buscan

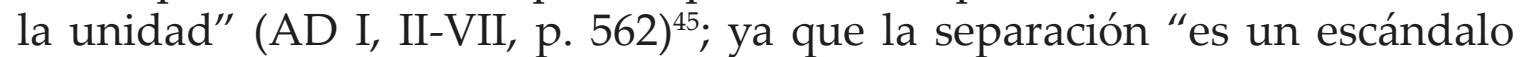
para los pueblos paganos e incluso para los fieles cristianos" (AD I, II-VII, p. 333-334 $)^{46}$. Con todo, no podemos hablar todavía de un ecumenismo propiamente dicho ${ }^{47}$. Además, estos vota deben ser interpretados en conjunto con el medio centenar de vota que, desde una perspectiva opuesta, ve en el avance del protestantismo un peligro para la fe y un motivo de grave preocupación, al modo como Leopoldo Buteler, obispo de Río Cuarto (Argentina), de alguna manera, sintetiza: "el protestantismo que tenemos en América es furiosamente proselitista, y se lanza a la campaña de lucha entre los católicos pretendiendo arrebatarles su Fe" (AD I, II-VII, p. 75).

También un buen número de obispos (en torno a 70) plantea la necesidad de abordar algunos temas que dicen relación con la postura de la Iglesia ante el mundo y la sociedad, si bien las orientaciones pueden ser bas-

\footnotetext{
${ }^{41}$ R. Pittini, arzobispo de Santo Domingo (República Dominicana), I. C. Maurer, arzobispo de Sucre (Bolivia), I. N. Almeida, arzobispo de Diamantina (Brasil), respectivamente.

${ }^{42}$ Cf. I. Borgatti, obispo de Viedma (Argentina) (AD I, II-VII, p. 87); M. Serrano, arzobispo de Cuenca (Ecuador) (AD I, II-VII, p. 10-11); C. Gouvêa Coelho, obispo de Niterói (Brasil) (AD I, II-VI, p. 219).

${ }^{43}$ S. Martínez, obispo auxiliar de Morelia (México).

${ }^{44}$ I. I. Mena, arzobispo de Asunción (Paraguay).

${ }^{45}$ J. A. Lebrum, obispo de Maracay (Venezuela). Cf. A. Zaplana, obispo de Tacna (Perú) (AD I, II-VII, p. 510).

${ }^{46}$ I. Martenetz, obispo auxiliar de Rio de Janeiro (Brasil).

${ }^{47}$ El concepto de "ecumenismo" solo aparece un puñado de veces (I. I. H. Porta, arzobispo de Asunción [Paraguay], [AD I, II-VII, p. 477]; A. Mendoza, obispo auxiliar de Abancai [Perú] [AD I, II-VII, p. 534]; G. M. de Morais, obispo de Juiz de Fora (Brasil) (AD I, II-VII, p. 200); solo un par de veces se habla de la Iglesia ortodoxa (I. Verolino, nuncio apostólico en Costa Rica [AD I, II-VI, p. 531-532]; A. Rodríguez, obispo de Santa Cruz de la Sierra [Bolivia] [AD I, II-VII, p. 116]); y una vez el tema aparece a la luz de la inmigración desde el oriente (R. I. Tavella, arzobispo de Salta [Argentina] [AD I, II-VII, p. 77]).
} 
tante diferentes entre sí. Es interesante analizar sus acentuaciones. Una buena mitad de ellos pide que se "compendie" o "confirme" 48 o incluso se "defina" 49 todo lo que la Iglesia ha enseñado respecto a la doctrina social. J. Bernal, arzobispo de Ciudad Bolivar (Venezuela), pide que se "acomode a los tiempos y problemas actuales" (AD I, II-VII, p. 557) y R. Arias, arzobispo de Caracas (Venezuela), ve la necesidad de exponer su "magnífica" doctrina "sobre todo acerca de la «cuestión obrera» $[. .$.$] y$ de otras cuestiones que se tratan en el mundo moderno, como acerca del capital de los medios de producción y el trabajo, o de los obreros" (AD I, II-VII, p. 555). También una mitad solicita que se trate más directamente sobre "la cuestión social" ${ }^{50}$, o "la cuestión agraria" - "la más apremiante de todas las cuestiones sociales que hay que resolver, al menos en América del Sur" (AD I, II-VII, p. 280) ${ }^{51}$ o algún otro tema social preocupante, sea para iluminar a los fieles, sea para orientar a la Iglesia como totalidad, dado que es una materia urgente: "Todos los obreros son generalmente pobres y la aplicación de la doctrina social católica es necesaria, porque la vida, en especial la de los hombres de campo, es miserable en lo referente al suelo y a la vivienda como en lo referente a la alimentación y educación de los hijos. Los patrones, en cambio, son latifundistas y tratan a los obreros más o menos como esclavos" (AD I, II-VII, p. 307) ${ }^{52}$. En todos estos obispos se manifiesta con claridad su preocupación por la situación social del pueblo latinoamericano. Sin embargo, es necesario tener presente que, de todos ellos, unos 20 asocian su preocupación social al temor al comunismo y otros 20 solo tiene una preocupación por el avance del comunismo ${ }^{53}$. Hallamos todavía otro grupo (unos 20) que piden sea definida con mayor claridad la relación de la Iglesia con el Estado ${ }^{54}$ - algunos incluso recuerdan "la doctrina íntegra" de Bonifacio VIII, "que se refiere a la Iglesia, el Estado y las relaciones mutuas entre ambos, ya desde un punto de vista especulativo, ya desde uno práctico" (AD I, II-VI, p. 241) 55 $^{55}$ ,- y desean que se reconozca "el influjo positivo" (AD I, II-VII, p. 101) ) $^{56}$

${ }^{48}$ Ej.: C. Rocco, nuncio apostólico en Bolivia (AD I, II-VII, p. 121); Conferencia Episcopal de Belo Horizonte (Brasil) (AD I, II-VII, p. 140); G. M. de Morais, obispo de Juiz de Fora (Brasil) (AD I, II-VII, p. 201).

${ }^{49}$ Ej.: D. Hostin y A. Niehues, obispo y obispo coadjutor de Lagos (Brasil) (AD I, II-VII, p. 204); A. Chacón, arzobispo de Mérida y A. Fernández-Feo, obispo de San Cristóbal (Venezuela) (AD I, II-VII, p. 566-567).

${ }^{50}$ Ej.: J. Pulido, obispo de Maracaibo (Venezuela) (AD I, II-VII, p. 562).

${ }^{51}$ I. Hascher, prelado nullius de Juruá (Brasil).

${ }^{52}$ I. de Lange, prelado nullius de Tefé (Brasil). Cf. L. Aguirre, obispo de Culiacán (México) (AD

I, II-VI, p. 188); I. da Mota e Albuquerque, arzobispo de Vitória (Brasil) (AD I, II-VII, p. 267).

${ }^{53}$ Cf. A. Jaramillo, Obispo de Jericó (Colombia) (AD I, II-VII, p. 408) y A. Rossi, obispo de Barra do Piraí (Brasil) (AD I, II-VII, p. 135), respectivamente.

${ }^{54}$ Ej: A. M. Barbieri, arzobispo de Montevideo (Uruguay) (AD I, II-VII, p. 545); G. Esorto, arzobispo de Bahía Blanca (Argentina) (AD I, II-VII, p. 52).

${ }^{55}$ F. Ruíz, arzobispo de Yucatán (México). Cf. M. Yerena, obispo de Huejutla (México) (AD I, II-VI, p. 217).

${ }^{56}$ A. Tortolo, obispo auxiliar de Paraná (Argentina). 
de su doctrina social y que la "naturaleza y amplitud de su magisterio" se extiende también a materias sociales y políticas (AD I, II-VII, p. 23) ${ }^{57}$. En el conjunto de esos 70 obispos se pueden observar dos acentuaciones diferentes: una más interesada en responder a una problemática acuciante en el continente, y otra más cercana a defender los derechos de la Iglesia frente a esa misma realidad. En este último caso se reclaman privilegios indebidos de parte del estado, por ejemplo, cuando F. Ruíz, arzobispo de Yucatán (México), afirma "el derecho divino, único y exclusivo de la verdadera religión, y la negación del mismo derecho para las falsas religiones" (AD I, II-VI, p. 241); y puede incluso llegar a darse - de manera del todo excepcional - quien añore una época de cristiandad ${ }^{58}$. Con todo, es importante resaltar - aunque sean un grupo pequeño (en torno a 10) - el hecho que algunos hagan presente la necesidad de una "reforma de la posición de la Iglesia frente a los obreros" (AD I, II-VII, p. 336) ${ }^{59}$, de una mayor preocupación por los pobres ${ }^{60}, \mathrm{y}$ también, de una mayor vida de pobreza en la Iglesia. Así, H. Golland, arzobispo de Botucatú (Brasil), pide "que la Iglesia de Cristo se vuelva a la fuerza de sus primeros años, a la simplicidad original del Evangelio [...] sea Iglesia pobre y humilde en cuanto a todas sus manifestaciones" (AD I, II-VII, p. 142) ${ }^{61}$.

\subsubsection{Sobre los miembros de la Iglesia}

Tres son los miembros de la Iglesia que suscitan una mayor atención de los obispos. De una parte, ven la necesidad de una reflexión doctrinal sobre el episcopado, que complemente lo que el Vaticano I no alcanzó a decir y, de otra parte, sienten la necesidad de restaurar el diaconado permanente y de potenciar el apostolado de los laicos, todo esto desde una sincera preocupación por la evangelización y misión de la Iglesia.

\section{Sobre los obispos}

Unos 50 vota mencionan la necesidad de tratar el tema de los obispos. La mayoría de ellos (unos 30) piden "establecer" o "definir la doctrina católica sobre el episcopado" (AD I, II-VII, p. 77) ${ }^{62}$, "determinando bajo la luz de la Revelación divina y de la santa Tradición, la potestad propia

\footnotetext{
${ }^{57}$ C. de la Torre, arzobispo de Quito (Ecuador).

58 "Si el Concilio Ecuménico presentara un programa positivo de acción contra-revolucionaria y de edificación de la Cristiandad con sus partes concretas, y convocara a los católicos a esta obra, pienso que llegaría la aurora del Reino del Sagrado Corazón de Jesús y del Inmaculado Corazón de María" (G. de Proença, obispo de Jacarézinho [Brasil]) (AD I, II-VII, p. 194-195).

${ }^{59}$ E. de Araújo Sales, obispo auxiliar de Natales (Brasil).

${ }^{60}$ Ej.: G. Adam, obispo de Valencia (Venezuela) (AD I, II-VII, p. 569); S. Martínez, vicario apostólico de Tarahumara (México) (AD I, II-VI, p. 249).

${ }^{61}$ Cf. E. Vicuña, obispo de Chillán (Chile) (AD I, II-VII, p. 351).

${ }^{62} \mathrm{O}$. Márquez, arzobispo de Puebla de los Ángeles (México). Cf. A. Aguirre, obispo de San Isidro (Argentina) (AD I, II-VII, p. 77).
} 
de los Obispos que, como sucesores de los Apóstoles, son los pastores propios de las Iglesias particulares y conforman la Jerarquía colegialmente unida con el Supremo Pastor" (AD I, II-VII, p. 23) ${ }^{63}$. Algunos (unos 15) piden también más específicamente "exponer" y "explicitar" el origen y los alcances de la potestad de los obispos ${ }^{64}$, ya que "el colegio episcopal, por divina institución, sucede al colegio de los apóstoles" (AD I, II-VI, p. $252)^{65}$. Y otros (unos 10) ven necesario darle mucho "mayor fuerza jurídica" a las conferencias de los obispos, tanto nacional, como regional y continental (AD I, II-VII, p. 163) ${ }^{66}$, dejando sentir, además, el anhelo de validar y afirmar más lo particular. Esto último se puede percibir en el deseo de "que el obispo sea elegido por el clero de la diócesis que debe presidir, de modo que sea fruto de la propia iglesia local" (AD I, II-VII, p. 201) ${ }^{67}$, porque es "doctrina tradicional que la diócesis junto a su Obispo cabeza es, como tal, el Cuerpo Místico de Cristo completo" (AD I, II-VII, p. 408) ${ }^{68}$.

\section{Sobre la restauración del diaconado permanente}

Más de 140 obispos piden estudiar la posibilidad de re-instaurar el orden del diaconado a laicos, normalmente estando casados, conforme al espíritu de la Iglesia primitiva y no camino al presbiterado. En general, se piensa en adultos, probados en la virtud, con trayectoria de servicio eclesial y que puedan predicar y celebrar los sacramentos que no necesiten el sacramento del orden. La razón es clara y casi unánime: la escasez de sacerdotes y las necesidades apostólicas, sobre todo, en tierras alejadas y de misión ${ }^{69}$. Alguno advierte de los problemas que podrían suscitarse, pero solo cinco, definitivamente, se oponen, sea porque bastarían buenos catequistas, o no se considera madura su reflexión ${ }^{70}$. Interesante es que hubo solo dos obispos del mundo que propusieron diáconos y diaconisas, ambos de Latinoamérica: I. Coelho, obispo de Maringá (Brasil) y L. de Uriarte, vicario apostólico de San Ramón (Perú) (AD I, II-VII, p. 214 y 531,

${ }^{63}$ C. de la Torre, arzobispo de Quito (Ecuador).

${ }^{64}$ Ej.: G. Bueno, obispo auxiliar de Taubaté (Brasil) (AD I, II-VII, p. 319); Conferencia Episcopal de Belo Horizonte (Brasil) (AD I, II-VII, p. 140).

${ }^{65}$ Jesús Alba, obispo auxiliar de México.

${ }^{66}$ B. Zorzi, obispo de Caxias do Sul (Brasil). Cf. G. Esorto, arzobispo de Bahía Blanca (Argentina) (AD I, II-VII, p. 50-51).

${ }^{67}$ G. M. de Morais, obispo de Juiz de Fora (Brasil).

${ }^{68}$ A. Jaramillo, Obispo de Jericó (Colombia).

${ }^{69}$ Ej.: Conferencia Episcopal de América Central y Panamá (AD I, II-VI, p. 523); A. Antezana y J. Gutiérrez, arzobispo y obispo auxiliar de la Paz (Bolivia) (AD I, II-VII, p. 110); A. Barbosa, obispo de campo Grande (Brasil) (AD I, II-VII, p. 154).

${ }^{70}$ Ej.: S. Mari, vicario apostólico de Riohacha (Colombia) (AD I, II-VII, p. 450). I. B. da Mota, arzobispo de Vitória (Brasil) resume esta problemática: “Todavía no aparece madura la cuestión sobre la restauración del diaconado, pero los catequistas, varones de grande piedad, tal vez constituidos en las órdenes menores, pueden hacer lo que no está prohibido por derecho divino: bendecir objetos de piedad e imágenes, bautizar al modo del diácono, distribuir la sagrada Comunión a los fieles, llevar el viático y asistir las exequias y los matrimonios" (AD I, II-VII, p. 268). 
respectivamente) ${ }^{71}$. Este último allí afirmaba: "Para que el apostolado crezca y se facilite cada vez más, que se instituyan hombres diáconos y también diaconisas que puedan predicar la Palabra del Señor, administrar la sagrada Comunión, de modo que se reserve a los sacerdotes solo lo que requiere el carácter sacerdotal, es decir la confección de la sagrada Eucaristía y la absolución en el sacramento de la penitencia. Que se permita el matrimonio a estos diáconos, el cual mientras perdure, impedirá que se llegue a ser sacerdote". En todo caso no es tan claro si todos están pensando en un grado del sacramento del orden o simplemente en un ministerio estable. De hecho, algunos hablan de "diaconado laical" (AD I, II-VII, p. 450) o de "diaconado de los laicos" (AD I, II-VII, p. 358) 72.

\section{Sobre el laicado y su apostolado}

El tercer miembro de la Iglesia que interesa al episcopado es el/la fiel cristiano/a laico/a y su colaboración en la tarea evangelizadora de la Iglesia. Unos 80 vota abordan diversos aspectos teológico-pastorales, que implican un cierto modelo de Iglesia. De ellos, unos 25 obispos piden reflexionar sobre "la naturaleza y acción", "los derechos y deberes" y sobre "la misión" de los laicos en general, "reconociendo su lugar propio" (AD I, II-VI, p. 547 y 534; II-VII, p. 77 y 73, respectivamente) ${ }^{73}$. A. Tortolo, obispo auxiliar de Paraná (Argentina) fundamenta el "apostolado de los laicos" en una "teología del carácter y de la gracia del bautismo y de la confirmación" (AD I, II-VII, p. 100-101). Tres obispos piden reflexionar sobre el sacerdocio "real", "universal" o "común" de los "fieles cristianos" o "laicos" (AD I, II-VI, p. 556 y 534; II-VII, p. 362 y 560, respectivamente) ${ }^{74}$. Por otra parte, más de 50 vota piden directamente "potenciar la participación de los laicos en el apostolado" (AD I, II-VI, p. 247) ${ }^{75}$, ya que "nunca como en nuestros días, hubo de desearse tanto [su] colaboración en el apostolado" (AD I, II-VII, p. 31) $)^{76}$. Varios desean promover su colaboración organizadamente, en grupos o dándoles un estatuto especial a ciertas misiones ${ }^{77}$. Otros indican labores más específicas de la tarea laical: "colaboración en la acción liberadora, sobre todo, entre los pobres", "en las relaciones con

\footnotetext{
${ }^{71}$ El Analiticus no reporta la intervención del obispo de Maringá sobre este tema (AD I, Appendix vol. II, 2, p. 121). Es verdad que, por lo escueto de la frase, tal vez también podría interpretarse como un ministerio no ordenado: "Institutionem Diaconum et Diaconissarum".

72 S. E. Mari, vicario apostólico de Riohacha (Colombia) y A. Silva, arzobispo de Concepción (Chile), respectivamente.

${ }^{73}$ I. Field, obispo de Saint George's-Grenada (Federación Británica del Caribe), A. Höfer, vicario apostólico de Limón (Costa Rica), A. Aguirre, obispo de San Isidro (Argentina) y J. Iriarte, obispo de Reconquista (Argentina), respectivamente.

${ }^{74}$ G. Viñamata, administrador apostólico de El Petén (Guatemala), A. Höfer, vicario apostólico de Limón (Costa Rica) y A. Silva, arzobispo de Concepción (Chile), respectivamente. ${ }^{75}$ L. Raimondi, delegado apostólico en México.

${ }^{76}$ A. Bruniera, nuncio apostólico en Ecuador. Cf. G. Mayer, obispo de Santa Rosa (Argentina) (AD I, II-VII, p. 84).

${ }^{77}$ Ej.: M. Casariego, obispo auxiliar de Guatemala (Guatemala) (AD I, II-VI, p. 562).
} 
los intelectuales", "en la administración económica", "en la asistencia de algunas ceremonias y ritos religiosos", en la catequesis y las parroquias y en otras acciones de suministro de la Iglesia, que deben ser "deberes de los fieles" (AD I, II-VI, p. 249; II-VII, p. 31 y 378; II-VI, p. 562-563; II-VII, p. 132, respectivamente) ${ }^{78}$. Es claro también que, en general, se sigue pensando (y algunos así lo explicitan) que su apostolado es una colaboración con "el apostolado de la jerarquía" (AD I, II-VI, p. 242) ${ }^{79}$. Finalmente, a todos esos vota habría que agregar otros 50 que se refieren a distintos aspectos - más bien disciplinares (como su incorporación al CIC) y de organización (como la focalización de su misión) - de la "Acción Católica", a fin de potenciar - como se concebía este apostolado - su colaboración con la jerarquía.

\section{Algunas conclusiones}

De todo lo dicho, podemos extraer algunas conclusiones todavía provisorias, pero indicativas de la autoconciencia eclesial de los obispos latinoamericanos previa al concilio. En primer lugar, desde una mirada estadística y, al menos, desde los números, en general se percibe que los obispos del continente se mostraron interesados en el concilio y activos en la colaboración con el acontecimiento anunciado. Pero sus respuestas fueron escuetas. Se pueden percibir dos razones de ello. Algunos sentían que no tenían grandes o importantes cosas que aportar, ya sea por su lejanía geográfica o eclesial, o por sus intereses más volcados a su particular vida concreta. Pero también es posible suponer - y percibir - que hubo quienes pensaron que ya estaba todo fundamentalmente preparado en Roma - no necesariamente en un sentido peyorativo - y que, por lo tanto, su palabra más específica era más bien superflua. Era una Iglesia todavía muy centrada en Roma y más bien pasivo-receptora en su relación con el primado.

Por otra parte, la inmensa cantidad de deseos, opiniones y sugerencias que tienen que ver con anhelos de reformas en la rúbrica litúrgica, en aspectos disciplinares, canónicos y pastorales, e igualmente de simplificación en la vida concreta del clero -aunque no por eso menos importantes -, nos muestra cómo los obispos se imaginaron el concilio en ese primer momento. Sin desconocer su portada dogmática, probablemente lo vislumbraron principalmente solucionando cosas prácticas, rápidas de resolver y muy consensuadas. Es decir, una reforma disciplinar, no teológica de la Iglesia. De hecho, los temas dogmáticos propuestos en el continente no son tan

${ }^{78}$ S. Martínez, vicario apostólico de Tarahumara (México), A. Bruniera, nuncio apostólico en Ecuador, J. Santos, obispo de Valdivia (Chile), M. Casariego, obispo auxiliar de Guatemala, I. Pires, obispo de Araçuaí (Brasil), respectivamente.

${ }^{79}$ R. Ruíz, arzobispo de Yucatán (México). 
numerosos y, en general, se suponen de amplio y ya adquirido consenso. Sus preocupaciones eran, más bien, eminentemente prácticas.

En tercer lugar, esa gran cantidad de sugerencias 'disciplinares', a partir de los intereses y preocupaciones reflejados, nos permiten también extraer algunas conclusiones. Los temas disciplinares más numerosos - liturgia y clero -, aunque ciertamente pueden ser interpretados de variadas maneras, con toda seguridad están mostrando que los obispos - tal vez todavía inconscientemente - perciben que existe una desadaptación de la Iglesia al continente y su cultura, expresada en la petición de la lengua vernácula, en la simplificación de la vida del clero y en hacer una liturgia mucho más adaptada a la comprensión del pueblo. Por ahora, no parecen ir mucho más allá que eso. Sin embargo, esa misma y simple percepción no está expresada con claridad en los temas teológicos (y eclesiológicos) que luego mayoritariamente piden sean tratados, que son tremendamente conservadores y, en general, no serán asumidos en el concilio en la perspectiva por ellos expresada en los vota. Por otra parte, es interesante que las reformas solicitadas - sobre todo las peticiones respecto al clero - estén orientadas hacia una vida más simple - diríamos más adecuadas al estilo del evangelio - lo cual también está indicando, inconscientemente, un cambio en la concepción del ser del clero y, por lo tanto, en ese contexto, significa también un cambio en la idea de Iglesia y de su misión. Ahora bien, si esto lo comparamos con el hecho de que la preocupación por condenar errores 'modernos' es relativamente menor - a excepción del comunismo, que responde también a otros factores -; y lo mismo ocurre con las preocupaciones acerca de temas éticos personales y de costumbres; tal vez podríamos concluir que, junto con expresar todavía una Iglesia bastante 'tradicional' y clerical, parece que, sin embargo, se comienzan a abrir algunas ventanas para pensar una Iglesia más simple, que mire más al pueblo y su sensibilidad, ya sea para que entienda y participe mejor en la liturgia, ya sea porque sus problemas sociales repercuten en la Iglesia y piden una misión que cumplir. En todo caso, esto tendrá que ser confirmado más adelante a partir de la explicitación de algunas preocupaciones dogmáticas, acordes a ese diagnóstico incipiente. Estamos todavía en una fase muy inicial - i-reflexiva - pero que empieza a orientarse correctamente. Lo que sin duda es claro, es que es en la praxis y en la vida eclesial en donde comenzamos a vislumbrar las promesas de cambios; y será precisamente ese el camino elegido en el futuro para la renovación eclesial.

Mirando ahora la doctrina eclesiológica explícitamente enunciada, resulta claro que para la generalidad de los obispos latinoamericanos el tema de la Iglesia era importante y requería su estudio, ya sea para complementar los temas que el Vaticano I no alcanzó a terminar -manteniéndose, en algunos, las mismas limitaciones del Vaticano I -, como también para reafirmar la teología del Cuerpo místico propuesta por Pio XII. El episcopado latinoamericano se encontraba completamente en sintonía con Mystici Corporis 
Christi. Y son escazas las propuestas de renovación que avancen más allá de esa eclesiología. Pero eso no quiere decir, necesariamente, que no había corrientes de renovación eclesiológicas en el continente. Solo que no estaban en las aulas - y por eso tampoco en la conciencia teológica explícita de los obispos -, sino fundamentalmente, como ya hemos mencionado, en la praxis. Eso se puede percibir - por cierto indirectamente - en dos temas eclesiológicos que son verdaderamente nucleares, pero que se enfocan desde lo práctico. El primero de ellos es la necesidad de avanzar en la unidad de los cristianos. El tema lo suscita, la mayoría de las veces, la presencia creciente de las Iglesias pentecostales, lo cual preocupa porque significa, en una buena cantidad de casos, el abandono de la Iglesia Católica; pero también la división se percibe, a partir del evangelio, como un escándalo y daño para la evangelización. Tras eso se está abriendo la conciencia de una Iglesia que es más que la institución, que nace desde el bautismo y que posee elementos comunes con otras comunidades cristianas. El hecho del paulatino "paso" de muchos católicos/as a otras formas de cristianismo fue obligando a revisar la propia forma de ser Iglesia. Y eso fue importante para la Iglesia del continente. Y el segundo tema es la relación de la Iglesia con el mundo. Es verdad que, en varios casos, aparece desde la preocupación por su relación con el estado; pero esos vota son mucho menos numerosos que los que piden una mayor preocupación por la cuestión social y la doctrina social de la Iglesia. Ello tampoco es una gran novedad con respecto al desarrollo del tema durante todo el siglo XX en el mundo, pero se deja ver una preocupación importante por la situación de pobreza del continente, que de alguna manera cuestiona también a la Iglesia. Esto se acentúa en los pocos, pero notables obispos, que se preocupan de la pobreza como realidad eclesial y de los pobres como destinatarios de la evangelización. No estamos todavía en la Iglesia pos Medellín, pero algo de eso está en ciernes en su sensibilidad a la cuestión social. Todo esto está mostrando, por otra parte, que no es cualquier preocupación eclesiológica práctica la que interesa a la Iglesia del continente, sino especialmente aquella que se relaciona con la cuestión social y con la evangelización. Esto significa, que es una Iglesia que empieza a poner las bases para entenderse a sí misma y su misión, ya no desde sí misma, sino desde su relación con el mundo, particularmente con los que necesitan de su palabra, de su acción y de su compañía. Nada de esto es explícito, pero se comienza a orientar en esa dirección.

Y con respecto a los miembros de la Iglesia, se destacan tres (obispos, diáconos y laicos/as), pero por distintas razones. El primero de ellos - el episcopado - tiene raíces directamente eclesiológicas. Se trata de completar la doctrina primacial del Vaticano I, pero más directamente, se percibe la necesidad de fortalecer su autonomía y autoridad en sus propias Iglesias locales y también de manera más regional. Los obispos de la región perciben con toda claridad la necesidad de una mejor teología y praxis episcopal, si bien, eso se expresa fundamentalmente en el tema de su autoridad. 
La preocupación por la restauración del diaconado permanente y por el apostolado de los laicos, aunque nace de una preocupación ciertamente evangelizadora, está tremendamente marcado por el factor "escasez de clero": se trata de responder a las necesidades de la evangelización y, ya que se carece de suficiente clero, se proponen cambios tales como la presencia de diáconos "casados" o nuevas formas de participación de los laicos/as en el apostolado de la Iglesia. Aquí la misión determina la estructura eclesial (y luego invitará a repensar la propia teología), lo cual es un principio destinado a dar muchos frutos en el continente, en donde las necesidades pastorales y sociales irán mostrando los cambios necesarios de implementar. Es la inversión hermenéutica - que será tan fecunda en el continente - que hace comprender la esencia a partir de la acción. No solo la acción sigue al ser, sino que también el ser depende de la acción. Las peticiones con respecto a una mejor reflexión sobre la participación de los laicos en la tarea evangelizadora de la Iglesia están en esa misma línea de pensamiento, a pesar de que también es todavía muy incipiente.

Finalmente - post factum - uno podría descubrir en las acentuaciones mencionadas, algunas de las líneas que - a través del desarrollo conciliar - aparecerán luego en Medellín y que aquí están solo en un momento germinal: el papel de la Iglesia particular y regional - expresado aquí en el fortalecimiento del rol episcopal frente al primacial; el dejarse cuestionar por los desafíos del mundo - expresado aquí por la preocupación por la cuestión social; y la inversión hermenéutico-pastoral para determinar los cambios necesarios en la estructura - expresado aquí en los casos concretos en donde la misión determina cambios disciplinares y canónicos. Con todo, hay que reconocer que todo esto es muy incipiente. Sin embargo, esas preocupaciones estaban mostrando una sensibilidad que solo necesitaba de la experiencia y teología conciliar para desplegarse novedosamente como lo haría en los años siguientes.

Entonces ¿hay novedades propias de Latinoamérica en los vota? A nivel de contenidos, en general, no, porque son semejantes al resto del mundo. Pero denotan una actitud novedosa que, con la experiencia del concilio, dará abundantes frutos que se expresarán en Medellín y su posteridad. La novedad está dada, entonces, por el nuevo talante eclesial que empieza a despuntar en el continente y que está caracterizado por su naciente permeabilidad al contexto. Había actitudes y sensibilidades que estaban esperando una experiencia eclesial y del Espíritu que las hiciera brotar para transformarse en teología y proyectos pastorales explícitos. Eso fue precisamente el concilio Vaticano II. Y esa experiencia, en muchos sentidos, cambió a los obispos, pero porque estaban abiertos para una tal experiencia. 


\section{Referencias}

CONCILIO VATICANO II. Acta et documenta concilio oecumenico Vaticano II apparando [AD]. Series I (Antepreparatoria): Consilia et vota episcoporum ac praelatorum. Vaticanus: Typis Polyglottis Vaticanis, 1960-1961, v. II, pars I, VI y VII.

CONCILIO VATICANO II. Acta et documenta concilio oecumenico Vaticano II apparando [AD]. Series I (Antepreparatoria): Studia et vota universitatum et facultatum ecclesiasticarum et catholicarum. Vaticanus: Typis Polyglottis Vaticanis, 1961, v. IV, pars II.

CONCILIO VATICANO II. Acta et documenta concilio oecumenico Vaticano II apparando [AD]. Series I (Antepreparatoria): Analyticus conspectus consiliorum et votorum quae ab episcopis et praelatis data sunt. Vaticanus: Typis Polyglottis Vaticanis, 1961, Appendix voluminis II, 2 partes.

CONCILIO VATICANO II. Acta et documenta concilio oecumenico Vaticano II apparando [AD]. Series I (Antepreparatoria): Indices. Vaticanus: Typis Polyglottis Vaticanis, 1961.

CONCILIO VATICANO II. Acta synodalia sacrosancti concilii oecumenici Vaticani II [AS]. Volumen II (Periodus secunda). Vaticanus: Typis Polyglottis Vaticanis, 1973, Pars V.

CALDEIRA, R. C. Um bispo no Concílio Vaticano II. Dom Geraldo de Proença Sigaud e o Coetus Internationalis Patrum. Revista Eclesiástica Brasileira, Petropólis, v. 71, n. 282, p. 390-418, 2011.

FOUILLOUX, E. La fase antepreparatoria (1959-1960). El lento camino para salir de la inercia. In: Alberigo, G (Dir.). Historia del Concilio Vaticano II. Salamanca: Sígueme, 1999. v. I, p. 63-154.

MA LlimA CI, F. Argentina. In: Beozzo, J. O. (ed.). Cristianismo e iglesias de América Latina en vísperas del vaticano II. San José: DEI, 1992. p. 97-120.

MELLONI, A. Per un approccio storico-critico ai consilia et vota della fase antepraeparatoria del Vaticano II. Rivista di storia e letteratura religiosa, Firenze, v. 26, n. 3, p. 556-576, 1990.

POLANCO, R. Cambios en la conciencia eclesial en América Latina, previo a la Conferencia de Medellín (1968). Estudio a partir de la literatura clasificada en la base de datos Seladoc. Cristianesimo nella storia, Bologna, v. 41, n. 1, p. 171-224, 2020.

Artículo sometido en 22.09.2020 y aprobado en 10.12.2020.

Rodrigo Polanco es doctor en teología (Universidad Gregoriana, Roma) y actualmente profesor titular de la Facultad de Teología de la Pontificia Universidad Católica de Chile y director de la Revista Teología y Vida. Su especialidad es la eclesiología y, particularmente, el Concilio Vaticano II y la teología latinoamericana. Orcid.org/0000-0003-3549-8040. E-mail: rpolanco@uc.cl.

Endereço: Pontificia Universidad Católica de Chile

Av. Vicuña Mackenna 4860

7820436 - Santiago - Chile 